\title{
Improving Liquidity in Secondary Spectrum Markets: Virtualizing Spectrum for Fungibility
}

\author{
Marcela Gomez, Member, IEEE, Martin Weiss, Member, IEEE, \\ and Prashant Krishnamurthy
}

\begin{abstract}
Pricing mechanisms in the form of auctions have been the main method for spectrum assignment in the U.S. for over 20 years. The spectrum auctions carried out by the Federal Communications Commission (FCC) constitute a primary market for spectrum and have been affected by lack of flexibility which has resulted in inefficiencies in spectrum assignment, especially in environments where spectrum is considered scarce. In recent years, we have observed significant efforts to increase efficiency in spectrum assignment and use. Among those efforts is the design and adoption of secondary markets. Secondary markets have the potential to address inefficiencies arising in primary markets over time or those that occur through features of auction mechanisms by enabling spectrum to be assigned to users who value it the most. Furthermore, liquid secondary markets have enabled the explicit management of risk in other markets, such as agriculture and commodities, through futures and options trading.
\end{abstract}

In this paper, we advance the study of liquidity in secondary markets that was begun in our previous work. We explore (i) the reasons that may have hindered the emergence of liquid secondary markets for radio spectrum and (ii) what we might change to promote secondary markets. With these objectives in mind, we study various configurations for the design of secondary markets, which account for the physical constraints inherent to electromagnetic spectrum. In addition, we study technical alternatives that would permit us to develop an appropriate, tradeable, spectrum-related commodity. The results of our analysis show that lack of fungibility has an adverse impact on secondary market liquidity. To address this outcome, we propose virtualization of spectrum resources into fungible chunks and show that this improves market liquidity by yielding viable market outcomes in all the scenarios we tested.

Index Terms-Secondary Spectrum Markets, Spectrum Virtualization, Spectrum Management, Spectrum Fungibility, Agent-based Modeling

The authors are with the Department of Informatics and Networked Systems of the School of Computing and Information of the University of Pittsburgh. Corresponding e-mails: mmg62@pitt.edu, mbw@pitt.edu and prashk@pitt.edu

\section{INTRODUCTION AND BACKGROUND}

Over the years, a variety of approaches to efficient and effective spectrum allocation and assignment have been adopted. Regulation was initially instituted to avoid harmful interference among spectrum users. The resulting spectrum policy separates spectrum use in space, time, and frequency (or electrospace [1]). Thus, an applicable band plan associates a license with a particular electrospace and defines what services may be provided [2]. As the importance of spectrum increases in society, researchers and policymakers have sought ways to increase access to and the utility of this resource while taking the challenge of harmful interference into consideration. Consequently, what traditionally required a license that was obtained through an administrative process may now be acquired through new mechanisms: licenses may be purchased, spectrum may be shared by several different users, or users may avail themselves of designated open access, unlicensed bands.

Licenses have the economic characteristics of a "property right"1, which led the Nobel Laureate Ronald Coase to argue in 1959 that a pricing mechanism should be used for resolving harmful interference rather than administrative procedures [7]. He pointed out that under a proper definition and enforcement of property rights, the parties involved in a dispute could bargain over the allocation of rights. He effectively argued that markets could efficiently assign spectrum to the highest valued uses, as they do with many other scarce resources. In the specific case of the U.S., the Federal Communications Commission's (FCC) approach to spectrum management

\footnotetext{
${ }^{1}$ Economically, property rights can be thought of as a social construct necessitated by our desire to separate ownership and decisionmaking as a consequence of economic specialization [3]. In fact, this notion really refers to a bundle of rights [4], [5]. It is also important to note that the "property rights" associated with spectrum allocations relate to usage rights rather than actual ownership rights [6].
} 
has evolved considerably since the 1920s. This includes the opening of unlicensed bands and the use of auctions to assign licenses. As we have argued elsewhere, these are some mechanisms that may be used in the governance of a common pool resource [4].

About 25 years ago, regulators began implementing Coase's recommendation by assigning radio spectrum licenses through economic rather than administrative means. Since then, many spectrum auctions have been conducted worldwide. These auctions are the primary markets for spectrum, much like an initial public offering (IPO) for equity shares. Equity owners use secondary markets for a number of purposes, including valuing their current holdings, adjusting their holdings through purchases or sales, writing derivative financial instruments (e.g. put and call options), etc.

The FCC recognized the importance of secondary markets in their 2002 Report and Order [8] and sought to build a framework to enable them. They framed secondary markets not as a substitute for spectrum auctions but rather as a means to correct possible inefficiencies resulting from the primary market and an alternative for carriers to respond to changing technologies and market conditions. Thus, secondary markets were expected to help alleviate spectrum scarcity by making underutilized spectrum held by current licensees readily available to new uses and users, hence promoting the development of novel and more spectrum efficient technologies. ${ }^{2}$ As pointed out in [6], "[w]ell functioning secondary markets can help ensure that, as demand and supply shift, spectrum will migrate to more efficient uses, including those by parties outside of the initial allocation".

In this paper, we examine an approach for acquiring spectrum usage rights through a secondary market mechanism. Our work focuses on the complexity of defining spectrum as a market commodity, which calls for a thorough examination of the conditions that would yield positive market outcomes (e.g.,

\footnotetext{
${ }^{2}$ See the statement of Professor Peter Cramton in the Secondary Market Forum of the Federal Communications Commission. May 31, 2000
}

market thickness ${ }^{3}$ and thus liquidity ${ }^{4}$. We build upon our previous work [10], [11] to understand the impact of non-fungible spectrum. In this way, we use agent-based modeling (ABM) to simulate secondary markts. We modified the ABM tool, called SPECTRAD, to take spectrum fungiblity into acccount through the fungibilty scores that we previously developed in [11], [12]. To facilitate the comparison with the previously reported work [10], [13], we made the smallest changes possible to SPECTRAD to implement this new functionality. The agent-based model developed for this paper seeks to evaluate how agents interact when they face spectrum fungibility constraints. Additionally, we propose a model where virtualized spectrum commodities may alleviate the limitations imposed by the lack of spectrum fungibility.

The remainder of our paper is organized as follows: in section II we include an overview of existing research work on the spectrum markets area and how our research differs from these publications; in section III we show how we adapt fungibility considerations to spectrum markets via fungibility scores; in section IV we explore how resource virtualization may improve market liquidity, and finally, in sections V and VI we present our conclusions and future research directions. Specific details on our approach to calculate fungibility scores have been included in Appendix A.

\section{RELATED WORK}

Since 2002, various researchers have focused on the development of secondary spectrum markets, attending to the challenges inherent to the commodity to trade, the market environment, and the technical characteristics of the systems where spectrum is utilized. In what follows we explore some of the

\footnotetext{
${ }^{3}$ An example of a thick market is the Amazon marketplace, which has a large amount of participants who are ready to transact with one another. Thickness results in more sellers being attracted by all the potential buyers and more buyers coming to this marketplace due to the increasing variety of sellers [9].

${ }^{4}$ The Palgrave Dictionary of Economics writes "A thin market is a market with few buying or selling offers. ... A thin market is characterized by low trading volume, high volatility, and high bid-ask spreads ... Market thinness is a particular source of market illiquidity. Liquidity is broadly defined as the ease of trading a security." http://j.mp/1pRJjHY
} 
existing approaches and how these differ from the focus of our research ${ }^{5}$.

Extensive work has been published on different types of auction mechanisms to enable dynamic spectrum access [14]-[18]. These works, and the citations therein, explore how various types of auctions may improve efficiency in spectrum assignment, allow buyers to more flexibly define the resources they need (e.g., auctioning spectrum as a continuous good instead of as a collection of discrete items), and how auction mechanisms may affect the bidding strategies of spectrum buyers as well as the revenue perceived by spectrum holders. For instance, the authors in [15], [16] focus on developing frameworks where truthful spectrum auctions can be used to enable spectrum reuse. Other proposals include the design of new auction mechanisms that increase the diversity of the users that obtain resources in an auction, thus exploring the trade-off between social welfare maximization and provision of minimum service guarantees [18].

An important research topic is the design of realtime spectrum markets, which have been studied in [19]-[22]. For instance, in [19], the authors explore the development of real-time secondary markets, where the primary license-holder is a GSM-based cellular carrier. Their main focus is to assess how this type of real-time trading mechanisms impacts spectrum utilization and performance of the primary license-holder, and whether this scheme is technically and economically viable. In [20], the study of markets is framed within the context of cognitive radio technologies. Besides real-time spectrum markets, the author also explores the concept of interruptible spectrum, which seeks to enable sharing of public sector spectrum in non-emergency conditions. In [23], the authors compare orthogonal (spectrum overlay) and non-orthogonal (spectrum underlay) sharing. The first scenario involves leasing of spectrum by a primary owner to secondary users as exclusive but temporary rights. In the second scenario, secondary users are allowed to transmit in the primary user's band and they are charged for the interference they cause. For their analysis, the authors consider only one primary user and one

\footnotetext{
${ }^{5}$ We do not claim that this section presents a complete survey of the literature and we acknowledge that there are far more works that have been developed in multiple areas of spectrum trading. In this section we focus on the works that are relevant to different stages of our research.
}

secondary user.

More comprehensive and complex network definitions that rely on spectrum trading are presented in [24]-[26]. These works do not necessarily rely on specific auction mechanisms; instead, they present additional settings where the benefits of marketbased approaches can enhance spectrum utilization. In a similar vein, in [27], the authors focus on optimization methods to explore markets where heterogeneous spectrum resources are leased by, and subsequently shared among secondary users. The authors consider a duopoly of wireless service providers that offer spectrum in distinct frequency bands. Secondary users opt for resources belonging to the service provider that maximizes their utility, which is calculated in terms of achievable link capacity and price. In [28], the authors study a dynamic market setting where a cognitive mobile network operator (C-MVNO) (sub)leases spectrum to unlicensed secondary users. The C-MVNO does not own spectrum, instead, it obtains resources by 1) sensing available spectrum holes and/or 2) leasing resources from current spectrum owners. Resource allocation from the C-MVNO to the secondary users is modeled as a Stackelberg game, where the cognitive operator is the leader. The objective of the cognitive operator is to determine the optimal amount of sensing and leasing it has to perform, and subsequently the optimal resource price it needs to set so as to maximize its profit. On the other hand, secondary users seek to maximize their utility which is a function of the required bandwidth and the price set by the C-MVNO. In other words, secondary users choose an amount of bandwidth depending on the price previously set by the cognitive operator. In both studies, [27] and [28], the price of resources is set by spectrum lessor (to a value that maximizes its profits); hence, secondary users cannot directly affect the price to pay.

In terms of how different market approaches have been tested, modeling has been a widely used mechanism. This is due to the lack of fully functional secondary spectrum markets in the real world. The objective of modeling that we are interested in consists on exploring how different market participants behave and how this influences market outcomes. In this context, game theory has been extensively utilized [29]-[31]. Another important method for 
modeling markets is agent-based modeling $(\mathrm{ABM})^{6}$. $\mathrm{ABM}$ has mainly been used for testing and desigining electricity markets. The work presented in [10], [13] is, to the best of our knowledge, one of the most thorough examples of using $\mathrm{ABM}$ to study the viability of secondary spectrum markets.

Our work differs from available publications in that we provide a throrough analysis on the fungibilty of spectrum by proposing a quantitative metric (i.e., fungibility scores) that could allow us to assess how the lack of spectrum fungibility impacts market viability. In computing the fungibility scores, we are interested in finding what bandwidth or capacity, at various frequencies, may be considered fungible or interchangeable (e.g., of the same economic value or perfect substitutes). Hence, we refined the initial calculation of fungibility scores (presented in [11]) and defined a metric to compare spectrum chunks in terms of the achievable capacity in different bands ${ }^{7}$. Further, in our effort to define spectrum as a tradeable commodity, we study how technical alternatives may render the thickness that markets need in order to be liquid. To this end, by relying on an existing and mature technology, we propose a model where virtualized spectrum commodities may alleviate the limitations imposed by the lack of spectrum fungibility.

Along these lines, the overall goal of our study is to present alternatives that can result in viable secondary spectrum markets. Our approach is to increase spectrum buyers' participation by providing them with a quantitative metric to assess how the resources available in the market compare to their preferred resources. In this way, potential buyers may be attracted to a marketplace that they would otherwise dismiss. From the perspective of market supply, our study also focuses on how we can leverage existing technologies to take a step closer toward commodifying spectrum, hence making it possible, for a frequency band, to fit a wider array of users and uses. In this manner, this study can be extrapolated to other types of auction mechanism and can be used as a basis for the design of different secondary spectrum market models.

\footnotetext{
${ }^{6} \mathrm{ABM}$ is a "form of computational modeling whereby a phenomenon is modeled in terms of agents and their interactions." [32]. In turn, agents are modeled with particular properties that determine their behavior and hence their interactions in the environment [32].

${ }^{7}$ A detailed overview on how fungibility scores are calculated has been included in Appendix A at the end of this paper.
}

\section{INCORPORATING SPECTRUM FUNGIBILITY} LIMITATIONS TO SECONDARY MARKETS

In this work, we incorporate fungibility scores in a trading environment to test the viability of secondary markets. We expect imperfect fungibility to have a negative impact on the liquidity of secondary trading markets. To assess the magnitude of this, we include fungibility scores as a key addition to the agent-based spectrum trading model, SPECTRAD [10]. We have focused on the frequency dimension of electrospace, so fungibility scores are a means to account for spectrum heterogeneity and frequency availability versus the specific band preferences of a market participant.

In what follows, we describe the market characteristics considered to develop a new version of SPECTRAD that would enable us to study the consequences of imperfect spectrum fungibility in a synthetic market.

\section{A. Market Model}

Throughout our analysis, we compare the results obtained with those presented in [13] to assess how market viability is affected by limited spectrum fungibility. Hence, we have maintained one of the market structures studied in [13], which we briefly detail in what follows:

1) Market Type: Using the market modeling alternatives presented in [10], [13], we focus on modeling a spectrum exchange with Band Manager (BM) functionality. The BM is a broker-like entity that holds, auctions and assigns the spectrum available in the market. Hence, the BM is also in charge of reclaiming the spectrum resources after the lease or license transfer periods have ended. A $\mathrm{BM}$ handles the process of granting authorizations for spectrum use; however, it is not responsible for the configuration of the radio equipment needed to make use of the acquired spectrum. We have chosen this market configuration as it allows us to have a middleman that can manage available resources, thus avoiding the overhead of direct interactions among all market participants. Additionally, this configuration allows us to center our attention on the definition of spectrum as a tradeable commodity.

2) Tradeable commodity: The commodity traded in this market is a basic (spectrum) trading unit which is referred to as basic bandwidth unit (BBU). 
In our model, BBUs consist of spectrum units of $200 \mathrm{KHz}$ of bandwith in the $1900 \mathrm{MHz}$ band.

3) Market Participants: Besides the Band Manager, spectrum license requesters (SLRs) also participate in the market. The SLRs' objective is to obtain a spectrum lease or license transfer to fulfill their traffic demand. We assume that every SLR has the infrastructure facilities to use the spectrum resources obtained in the market. Additionally, it is important to highlight that each SLR has a preferred frequency for providing its services, which could be different from the BM spectrum holdings (at the time of purchase $)^{8}$.

4) Spectrum Valuation: We focus on a model that takes into account the consequences of the lack of spectrum fungibility for market design and development. For this reason, we measure an SLR's spectrum valuation in terms of the difference between its preferred capacity and the capacity obtained in the market. Our specific approach consisted of limiting the maximum amount that an SLR is willing to pay for an available frequency using the corresponding capacity fungibility score.

The original SPECTRAD model defines a relationship between the amount that a user would pay for obtaining additional spectrum in the market and the price a user would pay for (or invest in) an alternate technology (AT) (e.g., wireline systems, investments to improve spectrum efficiency, unlicensed bands, etc.) that would allow them to fulfill specific traffic requirements. The inclusion of ATs frames the market process as part of a broader decision process that a secondary user faces (which has been elaborated more broadly by Cui et al. [33]). In this context, the price of ATs essentially sets a maximum price that a user is willing to pay for spectrum ${ }^{9}$. SPECTRAD allows different valuations for ATs for different users to capture the idea that different spectrum entrants may have different applications in mind. It is also important to note that SPECTRAD assumed that investments in ATs persist over several trading periods because they

\footnotetext{
${ }^{8}$ The participation of Spectrum License Holders (SLHs) is implicit in our model. We expect the BM spectrum holdings to stem from unused spectrum belonging to current incumbents i.e., SLHs. However, at this point of our analysis, we do not model their explicit interactions and dynamic changes in the market.

${ }^{9}$ Note that we assume that, for any given user, the performance (i.e., capacity) that it can obtain through AT investments matches the performance of their preferred frequency band (which may not be the same band available in the market).
}

are typically associated with capital investments that must be amortized.

The relationship between the willingness to pay for spectrum and ATs is presented in equation (1), where numBBUs and numATs correspond to the number of BBUs and AT units, respectively, needed for meeting specific traffic requirements. LimitPriceBBU and LimitPriceAT represent the maximum price a given user is willing to pay for BBUs or AT units, respectively.

$$
(\text { numBBUs })(\text { LimitPricePerBBU })=(\text { numATs })(\text { LimitPrice } A T)
$$

In turn, numBBUs and numATs are defined as the ratio between the traffic to serve and the capacity per BBU or AT, respectively. In other words, these represent the amount of spectrum or AT units needed to provide a specific service.

From these expressions and definitions, it follows that the maximum or limit price that a user will pay for a BBU is given by (2). In this expression, we observe that the measure of proportionality between the maximum price to pay for spectrum, LimitPrice $B B U$, and the maximum price to pay for ATs, LimitPrice $A T$, is given by the ratio of the capacity obtained with these two types of resources. In turn, this ratio corresponds to the (capacitybased) fungibility score we propose $(3)^{10}$.

$$
\begin{aligned}
& \text { LimitPrice } B B U_{=} \frac{\text { capacityPer } B B U_{\text {capacityPer } A T}}{\text { caimitPrice }_{A T}} \\
& \text { LimitPricePer } B B U_{=} \text {FungScore } \times \text { LimitPrice }_{A T}
\end{aligned}
$$

From (3), we expect that as the capacity fungibility score decreases, so does the maximum amount that users will pay for the spectrum available in the market. Thus, the level of comparability between two frequency bands drives the resource valuation, which we set to one of three levels: low, medium or high. These levels stem from dividing the range of fungibility values into three equally sized sets.

The maximum price per AT unit $\left(P_{A T}\right)$ also follows three valuation levels, which are distributed

\footnotetext{
${ }^{10}$ This definition complies with our assumption that in a certain degree, AT units and BBUs can be considered as perfect substitutes. In this way, $x$ BBUs provide the same level of utility (i.e., capacity) as $y$ AT units. This results in a linear relationship between these two factors, which further translates in a linear relationship in the maximum willingness to pay.
} 
in the range, $r_{P}$, between the minimum $\left(P_{A T \min }\right)$ and maximum $\left(P_{A T \max }\right)$ allowable AT prices $(4)$, as shown by expressions (5), (6) and (7). In this way, users in each valuation level will be assigned a uniformly distributed random value in the corresponding range.

$$
\begin{gathered}
r_{P}=\frac{\left(P_{A T \text { max }}-P_{A T \text { min }}\right)}{3} \\
P_{A T_{l}}=\left[\left(P_{A T \text { min }}\right),\left(P_{A T \text { min }}+r_{P}\right)\right] \\
P_{A T_{m}}=\left[\left(P_{A T \text { min }}+r_{P}+1\right),\left(P_{A T \text { min }}+2 \times\left(r_{P}\right)\right)\right] \\
P_{A T_{h}}=\left[\left(P_{A T \text { min }}+2 \times\left(r_{P}\right)+1\right),\left(P_{A T \text { max }}\right)\right]
\end{gathered}
$$

Note that in this non-perfect fungibility study, we shall allow that an SLR's spectrum valuation is inversely proportional to the same SLR's valuation of AT units. For instance, when an SLR has a low spectrum valuation, it will be assigned AT prices from the range belonging to $P_{A T_{h}}$.

From the previous section, it is possible to obtain a score for any pair of frequencies. For the purposes of our analysis, we focus on a 'worst-case' scenario where the SLRs have the lowest valuation for the available spectrum (i.e., the available frequency is $1900 \mathrm{MHz}$ while the SLRs' preferred frequencies are in the $700 \mathrm{MHz}$ band); hence, we used 0.3448 as the fungibility score for calculating the price limit expressed in (3). This value corresponds to the probabilistic fungibility score that results from comparing the capacity obtained with $1900 \mathrm{MHz}$ and $700 \mathrm{MHz}$ when both frequencies operate with a bandwidth of $200 \mathrm{KHz}$. A detailed explanation of this calculation is included in Apendix B2. Additionally, we have set $P_{A T \min }$ and $P_{A T \max }$ as 100 and 250 monetary units, respectively.

5) Market Transactions: The market transactions in SPECTRAD are driven by sealed-bid, secondprice auctions ${ }^{11}$. In the initial bidding round, each user will post a bid according to its own BBU and AT valuation level (i.e., private value), as explained in the previous subsection. If the demand is greater

\footnotetext{
${ }^{11}$ In sealed-bid, second-price auctions, the strategy of bidding one's highest value weakly dominates all other strategies. This stems from the fact that "bidding your maximum value leaves you as well off as, or better off than, bidding any other value. The amount that you bid affects whether you win, but it does not affect how much you pay if you win, which equals the second-highest bid" [34]. In other words, truthful bidding dominates an overbidding stategy.
}

than the supply, the bids are organized in descending order and the available resources are temporarily assigned to the SLRs with the highest bids. The minimum bid that temporarily receives resources is considered as the current auction cutoff price (i.e., clearing price), and it is announced to all SLRs. In this way, for each subsequent round, the SLRs have the option to adjust their bids according to the cutoff price in order to remain competitive in the market. The auction ends when we have not perceived a change in the cutoff price in the last five bidding rounds or when we reach a (predefined) maximum number of bidding rounds. At this point, the SLRs with bids above the cutoff price receive their requested resources until the BM supply is exhausted. The SLRs that could not obtain all the necessary spectrum units from the market will opt for an amount of AT units that could permit them to fulfill their traffic demand.

When the demand is not greater than the supply, there is no competitive bidding. Hence, all bidders receive their requested resources and they pay the minimum cutoff price established by the BM. In this particular scenario, it corresponds to 30 monetary units.

\section{B. Simulation Environment}

We have maintained the agent-based simulation environment and running considerations made in $[13]^{12}$. For market evaluation, we have considered different combinations of spectrum users (SLRs) and spectrum supply conditions (i.e., under supply and oversupply). To quantify the latter, we consider an additional parameter, $R$, defined in (8). In this equation, tot $B B U s$ corresponds to the amount of spectrum bandwidth units available in the market and numSLRs refers to the number of market participants in a particular scenario. In this way, lower values of $\mathrm{R}$ represent spectrum undersupply conditions, while higher values of $\mathrm{R}$ correspond to spectrum oversupply.

$$
R=\frac{\operatorname{tot} B B U s}{\text { numSLRs }}
$$

\footnotetext{
${ }^{12}$ The original and revised versions of SPECTRAD were developed in Java and they run using REPAST Simphony, an agent-based modeling platform that works with the Eclipse IDE. Full information on REPAST Simphony can be found in http://repast.sourceforge.net/repast_simphony.php
} 
TABLE I: Simulation Parameters for the Modified Version of SPECTRAD

\begin{tabular}{|c|c|}
\hline $\begin{array}{c}\text { Number of Market } \\
\text { Participants }\end{array}$ & $\begin{array}{c}\text { numSLRS }= \\
\{4,5,6,10,20,50\}\end{array}$ \\
\hline $\begin{array}{c}\text { Distribution of Users' } \\
\text { Spectrum Valuation }\end{array}$ & $\begin{array}{c}\text { All users have low } \\
\text { spectrum valuation, which } \\
\text { corresponds to a high AT } \\
\text { valuation }\end{array}$ \\
\hline Available Spectrum & $\begin{array}{c}\text { Calculated using (8), } \\
\text { where } \\
\end{array}$ \\
Market Type & $\{5,10,15,20,25\}$ \\
\hline & Band Manager \\
& Exchange-based market \\
\hline
\end{tabular}

The specific parameters that have been tested in the new version of SPECTRAD are presented in Table I.

\section{Viability Criteria}

In [13], a set of viability criteria was determined taking into account characteristics that are desirable for market liquidity. Unless otherwise stated, to obtain the final values of each of these criteria, we calculated the average of the relevant parameters across all simulation runs.

Probability of empty bid list: The value of this probability stems from comparing the amount of bidding rounds where no users placed bids to the total number of bidding rounds in a given simulation run. High values of this criterion result from situations where the prices are too high in the market, the resources available are not suitable for the demand of the SLRs or the SLRs' current AT holdings are sufficient for fulfilling their demand. In this way, a large number of empty bid lists implies that there is insufficient interest in participating in the market; thus it is an adverse condition for market viability.

Probability of demand greater than supply: This factor allows us to compare the supply and demand levels in the market. A positive market condition is to have a large number of market participants opting for a large number of market commodities, which can actually be translated into market thickness ${ }^{13}$. Indeed, this means that the market participants are highly interested in the resources available. Hence, they are willing to participate in the market to obtain

\footnotetext{
${ }^{13}$ Roth points out that thickness is related to the readily availability of many buyers and sellers. In such a case, "[m]ore sellers will be attracted by all those potential buyers, and more buyers will come to this marketplace because of the ever-expanding variety of sellers" [9].
}

resources to fulfill their demand. From a market viability perspective, the higher the probability of the demand being greater than the supply, the more successful the market. As explained in what follows, this criterion also has an impact in the auction cutoff prices.

Average cutoff price: The cutoff price is a consequence of the conditions of demand and supply in the market. In fact, when the aggregate demand from the SLRs surpasses the available supply (i.e., BM holdings), a competitive bidding process arises for obtaining resources from the market. In this way, at the end of the auction, the available resources will be assigned to the users with the highest bids. The minimum bid that obtained resources from the market corresponds to the auction cutoff price ${ }^{14}$. This further implies that the resources are assigned to the users who value them most, thus fulfilling one of the main objectives of auctions. On the other hand, when the demand is not greater than the supply, all users will be assigned resources in exchange for the minimum payment established by the BM (i.e., there is no competitive bidding). This minimum payment, which becomes the final auction cutoff price, does not reflect the SLRs valuation of resources as this price does not stem from the SLRs bidding activity. In this way, higher cutoff prices indicate positive and competitive market conditions.

Average number of AT units per spectrum user: As previously explained, a market participant invests in AT units when it is not possible to obtain enough resources from the market to fulfill its demand. In this light, a positive market outcome has the majority of the participants providing their services with market commodities, thus keeping their AT holdings low.

Percentage of assigned bandwidth units: The calculation of this percentage allows us to compare the amount of resources assigned in the market to the entire market supply (i.e., the spectrum holdings of the BM). This factor is also a consequence of the levels of demand and supply in the market. As such, when the demand is greater than the supply, it is most likely that all the BM holdings will be assigned to the most competitive SLRs; however, when the supply exceeds the demand, it is unlikely that the BM will assign all of its resources. In this

\footnotetext{
${ }^{14}$ Note that since we are relying on a second-price auction, the final payment made by the auction winners corresponds to the bid that is immediately lower to the auction cutoff price.
} 
way, this percentage provides us with a measure of market efficiency in the assignment of resources and an additional means to evaluate the degree of market participation.

To evaluate quantitatively whether markets are viable, we define pass and fail values for each of the viability criteria. To this end, we observe the simulation results for the individual viability factors. Due to the relationship existing among these factors, we focus on the limit values associated with positive outcomes, and those that lead to a negative shift in the market conditions. This allows us to define, experimentally, pass / fail thresholds. In turn, the scores associated with "passing" and "failing" conditions represent how critical each factor is for the overall viability assessment. The thresholds and scores relevant to our market are defined in Table II ${ }^{15}$.

TABLE II: Viability Criteria and Market Scores

\begin{tabular}{|c|c|c|c|}
\hline Criteria & $\begin{array}{c}\text { Pass } \\
\text { Value }\end{array}$ & $\begin{array}{c}\text { Fail } \\
\text { Value }\end{array}$ & $\begin{array}{c}\text { Score } \\
\text { Pass/Fail }\end{array}$ \\
\hline $\begin{array}{llll}\text { P1 - } & \text { Bid } & \text { List } \\
\text { Empty } & & \end{array}$ & $<1 \%$ & $\geq 1 \%$ & $1 /-1$ \\
\hline $\begin{array}{lr}\text { P2 - } & \text { Demand } \\
\text { Greater } & \text { than } \\
\text { Supply } & \\
\end{array}$ & $\geq 10 \%$ & $<1 \%$ & $1 /-1$ \\
\hline P3 - Cutoff Price & N/A & $<31$ & $0 /-1$ \\
\hline $\begin{array}{l}\text { P4 - Percentage of } \\
\text { Assigned BBUs }\end{array}$ & $\geq 62 \%$ & $<62 \%$ & $1 /-1$ \\
\hline $\begin{array}{l}\text { P5 - Number of } \\
\text { ATs per User }\end{array}$ & N/A & $\geq 3$ & $0 /-1$ \\
\hline
\end{tabular}

\section{Results}

Our market viability results are derived from the analysis of one hundred simulation runs of each market scenario, each being active for 5000 time ticks ${ }^{16}$. The first 3000 time ticks were used as a warm up period, and the data for analysis was extracted from the last 2000 time instances.

As previously stated, our analysis focused on the 'worst-case' scenario, thus considering each SLR to have a low valuation of spectrum. Given that this valuation is directly related to the fungibility score, we performed a sensitivity analysis as a means to validate our results and further explore

\footnotetext{
${ }^{15}$ Note that this process is the same as that followed for the evaluation of the original version of SPECTRAD [13].

${ }^{16}$ Time ticks are the time units defined in the ABM simulation environment. These could be replaced with any suitable time representation.
}

the market behavior when the fungibility score changes. The market viability results presented in figure 1 contrast the following levels of spectrum fungibility: 1 or perfect fungibility; 0.3448 or calculated capacity fungibility score; 0.25 and 0.15 . The lower fungibility scores aim at considering further constraints that could be derived from the use of an alternative frequency, which are not only inherent to the changes in the achievable capacity [12]. For instance, these constraints could represent the cost that an SLR would need to incur for using a new type of technology that is compatible with the frequency bands acquired in the market.

The simulation results point to the combination of number of users and spectrum availability, expressed through $R$, that render viable markets. In this way, our results show that markets are viable when $5 \leq R \leq 10$. We did not obtain successful markets under spectrum oversupply conditions (i.e., $R \geq 15$ ). In turn, the number of users associated with market viability varies with the level of fungibility studied. Figure 1 summarizes the market viability scenarios we found in our simulations.

\section{E. Discussion}

Analyzing the results presented in Figure 1, we can observe that the number of viable markets decreases with lower fungibility scores. In fact, the number of viable markets ranges from 9 in a perfect fungibility scenario to 6 under lower fungibility conditions. Further, as the fungibility score decreases, not only we lose viable markets, but also, the actual viability score associated with our positive results diminishes.

Delving into particular viability parameters, we explore how they change as we vary the spectrum fungibility level. We find that the auction cutoff price falls as the fungibility level decreases. In the case of the percentage of BBUs that are assigned through the market, we find that this is consistent with demand and supply levels in the market (i.e., higher percentage of BBUs are assigned in higher supply conditions); however, this parameter remains relatively constant in spite of changes in spectrum fungibility. A complementary parameter, the amount of ATs assigned in the market, shows a significant drop of as we switch from perfect fungibility to our calculated value; however, as the fungibility level continues to drop, this value stabilizes. These results 

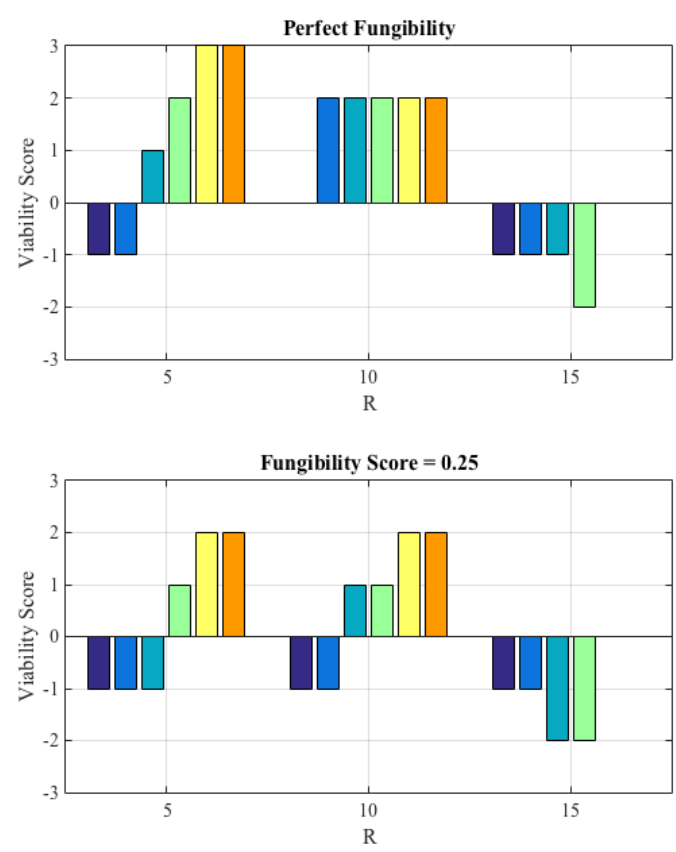
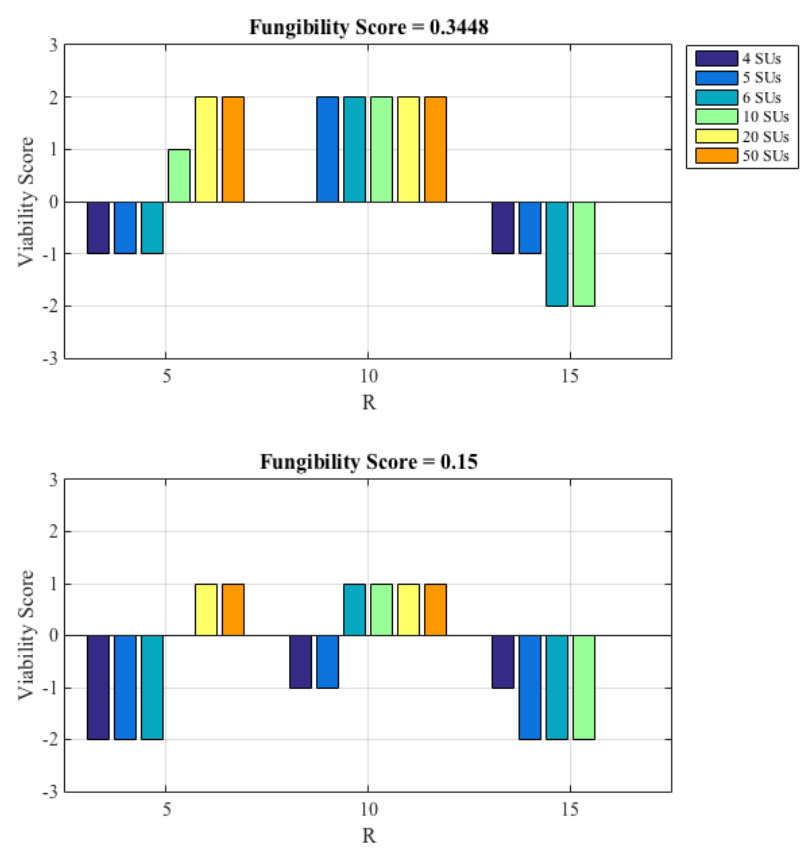

Fig. 1: Average market viability scores for different levels of spectrum fungibility.

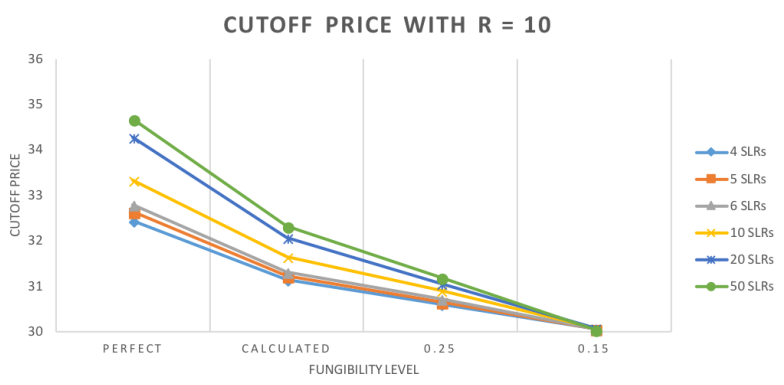

Fig. 2: Auction cutoff price when $\mathrm{R}=10$

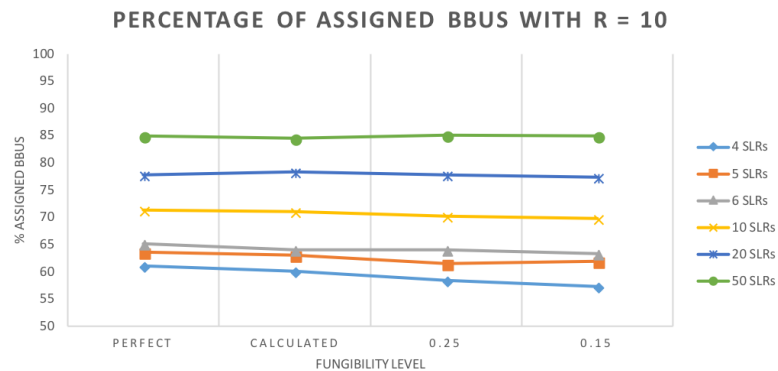

Fig. 3: Percentage of Bandwidth units assigned when $\mathrm{R}=10$

are portrayed in Figures 2, 3 and 4, respectively, for the case where $\mathrm{R}$ is equal to 10 .

It is important to note that our overall results show that for markets to be viable, we require at least five market participants with a moderate

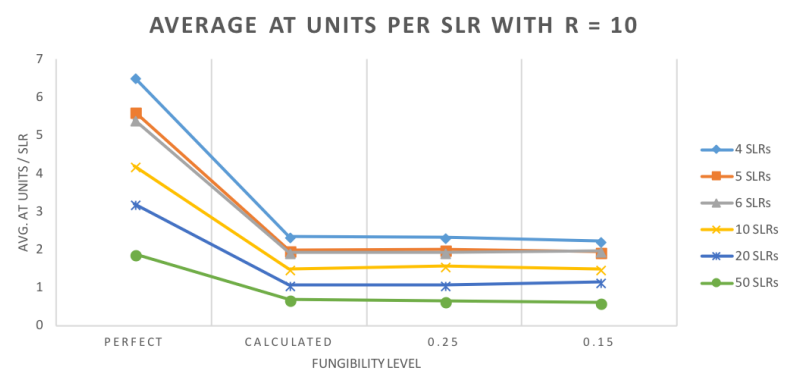

Fig. 4: Average number of AT units per SLR when $\mathrm{R}=10$

amount of spectrum available for trade. However, if we consider the current structure of the telecommunications market, we can observe that in most cases we only have a few stakeholders covering the majority of the market. Hence, our results indicate that it is rather unlikely that these market configurations would emerge in practice.

In order to test the influence of $P_{A T}$ in market viability, we tested a different scenario where $P_{A T}$ follows a long-tailed distribution ${ }^{17}$. This new assumption changes the range of values that users hav-

\footnotetext{
${ }^{17}$ To implement this, we assumed that the range of possible values for $P_{A T}$ followed a pareto distribution and each value would occur with the corresponding probabilities. In this way, we modified the poportion for low, medium and high AT valuation thresholds. Note that we still maintained our assumption that the willingness to pay for BBUs is inversely proportional to the willingness to pay for ATs.
} 
TABLE III: Resulting auction cutoff prices when $P_{A T}$ follows a long-tailed distribution

\begin{tabular}{|c|c|c|c|c|}
\hline & \multicolumn{3}{|c|}{ SLRs } \\
\hline & & 4 & 6 & 10 \\
\hline \multirow{3}{*}{$\mathbf{R}$} & 5 & 32.8 & 33.6 & 35.5 \\
\hline & 10 & 31.27 & 31.87 & 32.06 \\
\hline & 15 & 30.4 & 30.43 & 30.27 \\
\hline
\end{tabular}

ing a low, medium and high valuation for spectrum and ATs can set as their price to pay. We used the calculated fungibility score (i.e., fungibility score $=$ 0.3448 ), and we still tested the worst-case scenario, where all SLRs have a low valuation for spectrum. All other parameters of the model followed the description presented in Sections III-A and III-B. Additionally, the results were evaluated using the viability criteria detailed in Section III-C. In Figure 5 , we compare the results obtained with a uniform and long-tailed distribution of $P_{A T}$. For comparison purposes, we show the viability scores for the cases with 4, 6 and 10 SLRs, where $5 \leq R \leq 15$. As it can be observed, our new results show variations in the market viability scores; however, none of these variations imply a shift from non-viable to viable market conditions or vice versa. In other words, changing the distribution of the SLRs' willingness to pay does not necessarily impact the overall viability of the market in our model. The results obtained also show that the auction clearing price obeys demand and supply conditions. As presented in Table III, in spectrum under supply conditions (i.e., $\mathrm{R}=5$ ), the cutoff price is higher in all cases. Nevertheless, the cutoff price drops as the values of $\mathrm{R}$ indicate higher supply conditions. Indeed, in the case of $R=15$, the cutoffprice presents small variations with respect to the auction reserve price, which is 30 monetary units.

The overall analysis performed with this new market model led to the next step in our research. Developing viable spectrum markets meant finding a new, tradeable, spectrum-related commodity that would provide greater market liquidity while fully satisfying the requirements of spectrum buyers.

\section{FINDING THE APPROPRIATE COMMODITY TO TRADE}

The next stage of our research has focused on finding a commodity that would increase market thickness and liquidity, thus allowing us to create

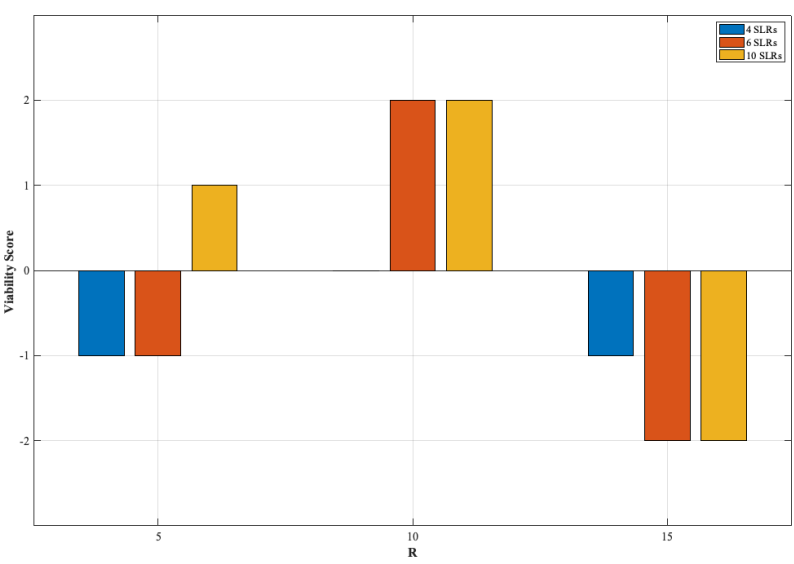

(a) Uniform Distribution of $P_{A T}$

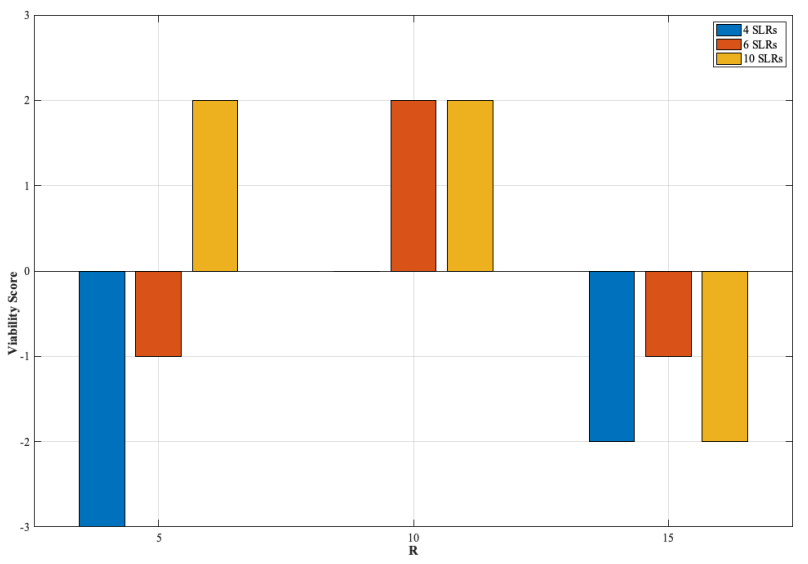

(b) Long-tailed Distribution of $P_{A T}$

Fig. 5: Comparison of Viability Scores for uniform and long-tailed distributions of $P_{A T}$

market models that would be successful in conditions that resemble existing market scenarios. That is, we require a technical means to bypass some of the physical constraints of electromagnetic spectrum while maintaining its capabilities for service provision. In [35], we explore the opportunities that could be derived from wireless network and resource virtualization and further applied to our market scenario. Essentially, we analyze the possibility of developing a market in which the traded commodity is no longer "naked" spectrum, but instead, units of virtualized spectrum. In essence, we seek a tradeable commodity as close to the physical layer as possible but still above it. To this end, we have framed this virtualized market analysis within the concepts and guidelines of LTE-Advanced. This has enabled us to explore the degree of technical feasibility of the 
promising concepts of virtualization ${ }^{18}$.

In subsection IV-A we present some of the relevant details about virtualization and LTE-A that have been particularly useful for the development of our new market model.

\section{A. Technical Background}

1) Wireless Network and Resource Virtualization: Wireless Network and Resource Virtualization has been the target of a significant amount of research in different directions, which map to the multiple layers that are involved in telecommunications networks. From a Computer Science perspective, virtualization is defined as "any form of partitioning or combining a set of network resources, and presenting (abstracting) it to users such that each user, through its set of partitioned or combined resources has a unique, separate view of the network" [36]. Adopting a more general point of view, virtualization refers to the usage of a virtual version of something rather than the actual (original) thing itself [24]. Furthermore, we could associate the use of virtualized resources to the use of the Cloud, in the sense that, under virtualization, we would be dealing with an infinite number of resources, which are available on demand and without the need to incur in high upfront commitments [37].

Research shows that the interpretation and application of virtualization concepts can change according to the area of study and the scope and depth of the virtualization process [38]. In consequence, we can see how the initial definition of virtualization, in a Computer Science context ${ }^{19}$, has changed and continues to evolve according to the specifics of the underlying network and the goals we pursue.

Numerous applications and models of virtualization have been studied. For the purpose of this research, we focused on a specific virtualization approach that contemplates the creation of resource pools. These pools are formed through the aggregation of resources belonging to multiple wireless networks and thus operators. The pooled resources are later made available to a larger set of operators,

\footnotetext{
${ }^{18}$ Note that our objective is to find existing technical means that would make it possible to define homogeneous commodities, thus creating a realistic fungibility environment. In this vein, our focus is not to develop a technical proposal on how LTE-A PRBs may be converted in tradeable commodities.

${ }^{19}$ For a thorough analysis of Virtualization in a Computer Science context, please refer to [36].
}

who will provide a specific type of service to their end users. As expected, these resources could be any shareable part of the network (e.g., infrastructure, electromagnetic spectrum); nevertheless, given that the focus of our study comprises the development of spectrum markets, we have considered pools formed only by electromagnetic spectrum resources in this stage.

Through this type of virtualization, we could expect the rise of networks that can foster a greater number of spectrum users due to increased opportunities for using, sharing, accessing and assigning the existing resources [35]. In turn, operators could obtain the required capabilities for expanding or shrinking their networks, as needed and without incurring in prohibitive costs [39].

In order to add thickness to the market, we further require the pooled spectrum resources to have a higher level of granularity and flexibility. For this reason, we appealed to the possibilities for resource management provided by LTE-Advanced. By framing our virtualization approach within an existing and mature technology such as LTE-A, we can further bring our study closer to practical scenarios.

2) LTE-Advanced: One of the main objectives of the deployment and usage of LTE is the creation of more flexible spectrum allocation mechanisms in existing or newly available frequency bands. Further, this technology was designed for allowing the co-existence between current and legacy radio technologies [40]. With its further evolution into LTE-Advanced, we are provided with the possibility to aggregate multiple carriers and thus obtain wider bandwidths ${ }^{20}$. In this light, LTE represents an appropriate addition to the technical framework that we require for enhancing our spectrum market model.

In LTE, the basic element for radio resource allocation is the Physical Resource Block (PRB). The PRBs are sets of resource elements ${ }^{21}$, which are time-frequency resource units used for uplink and downlink transmission. The minimum radio resource unit that can be allocated corresponds to one subframe of 1 millisecond, which is comprised by two PRBs. These subframes can be aggregated into 10 millisecond LTE-frames. In the frequency

\footnotetext{
${ }^{20} \mathrm{http} / / /$ www.3gpp.org/technologies/keywords-acronyms/97-lteadvanced

${ }^{21}$ Resource elements can be defined as one sub-carrier over one OFDM symbol [40]
} 
domain, we shall remember that each PRB maps to 12 subcarriers of $15 \mathrm{KHz}$ each, which adds up to $180 \mathrm{KHz}$.

We can easily observe how the number of PRBs that are allocated to a given user translate into the bandwidth that can be utilized for a particular transmission. The total amount of PRBs that can be allocated to any user obeys to the LTE standard ${ }^{22}$. For situations in which larger amounts of bandwidth are required, we can appeal to the carrier aggregation capabilities provided by LTE-A. Under such scheme, we can sum up to $100 \mathrm{MHz}$ of bandwidth utilizing contiguous and non-contiguous spectrum deployments. These large bandwidths can be built by aggregating up to five component carriers of different individual bandwidths ${ }^{23}$. We have kept the aforementioned characteristics of PRBs and LTE-A parameters for downlink transmission as the basis for the definition of the spectrum related commodity to be traded in our market model.

\section{B. New Market Model}

For this new analysis, we have maintained the general design and characteristics of the previous market model. Thus, we still consider the same type of market, market participants and market transactions. The major change lies in the definition of the commodity that will be traded in the market.

The new market commodity: For the new market commodity we consider a set of virtualized spectrum resources which have been aggregated in a pool. For the actual virtualization process, we take advantage of the resource allocation process used by LTE-A, which allows us to map PRBs to specific values of bandwidth and in turn transform that bandwidth into corresponding values of capacity (in bps). We follow the standard guidelines for the number of PRBs that can be assigned, with their associated bandwidth and, for our trading purposes, we calculate the resulting capacity using equations

\footnotetext{
${ }^{22}$ The reader is referred to [41] for a thorough definition of LTE-A associated parameters and metrics.

${ }^{23}$ The added flexibility derived from the utilization of carrier aggregation implies a technical cost, which is the result of the fragmented nature of the spectrum, and thus bandwidth, that has been reserved for this technology. As a consequence, we would require the equipment and user terminals that will be handling the variable, aggregated bandwidth to have the appropriate filtering, processing and decoding capabilities [40], [41]. This certainly translates into the need to develop more complex equipment, with the associated challenges and costs.
}

(12) and (13). We relied on the COST 231 WalfischIkegami model to obtain the signal level applied to equation (12). This time, the frequency parameters for the propagation models are the applicable LTE frequency bands and bandwidths. The remaining parameters are still those included in Table VI. Note that, for our market purposes, we use a 10 millisecond-LTE frame as the minimum assigned unit.

Fungibility Conditions: LTE-A and its available bands in the U.S. have permitted us to frame our study within an existing fungibility environment. In this way, for the definition of our pool of resources, we considered three bands, of $10 \mathrm{MHz}$ each, with their center frequency in the $700 \mathrm{MHz}$ range. These approximately correspond to LTE bands 13 (746 $\mathrm{MHz}-756 \mathrm{MHz}), 14(758 \mathrm{MHz}-768 \mathrm{MHz})$ and 17 (734 MHz - 746MHz). These pseudo perfect spectrum fungibility conditions are derived, in this case, from the range similarity of these three bands and from our assumption that LTE-A capable devices should be able to tune to all these frequencies.

Following the original market model, we still use the definition of alternate technology (AT), which can be utilized by the SLRs in case they do not obtain (sufficient) spectrum from the market. In this particular case, we consider as an appropriate AT option the TV White Space (TVWS) spectrum in the $700 \mathrm{MHz}$ band.

\section{Simulation Scenarios}

We consider two different scenarios for evaluating market viability. These scenarios evaluate different duration periods of unlicensed spectrum (i.e., AT) usage. Our first approach is rather conservative, as we try to remain as close as possible to the initial SPECTRAD model. In this way, a given user would be able to hold these unlicensed spectrum units for a random period that will be uniformly distributed between 90 and 110 simulation time units ${ }^{24}$.

The second approach diverges from this random time assignment, now assuming that the usage of unlicensed spectrum will last the same period as a licensed spectrum lease (i.e., 10 milliseconds). This new interpretation permitted us to account for

\footnotetext{
${ }^{24}$ Lacking specific user data, the choice of distribution was arbitrary. In practice, we could expect this distribution to be nonlinear with peaks centerd around the typical switching costs between common ATs and spectrum BBUs.
} 
the possible degradation of service that users could experience when utilizing unlicensed spectrum, as well as their willingness to participate in the market once a new bidding round started.

In both scenarios, the market configurations we tested have been defined by the combination of a given number of spectrum users (SLRs) and a specific amount of available spectrum, using the variable $\mathrm{R}$ defined in (8). Nevertheless, we further limited the spectrum availability taking into account our LTE-band assumption. In this way, given that our model considers three $10 \mathrm{MHz}$ LTE bands, the spectrum pool we created could have a minimum of $18 \mathrm{PRBs}$ and a maximum of $150 \mathrm{PRBs}^{25}$.

To maintain consistency with the simulations of previous trading models, we ran this new simulation for 5000 time units (simulation time-ticks), from which 3000 were considered as warm-up period and the last 2000 provided us with the data for our analysis. Table IV shows the relevant parameters considered for our new model simulations.

\section{TABLE IV: SPECTRAD Model Parameters}

\section{General Model Parameters}

\begin{tabular}{|l|l|}
\hline $\begin{array}{l}\text { Bandwidth (occupied) of } \\
\text { the PRBs [MHz] }\end{array}$ & $\begin{array}{l}\text { Values permitted by the standard: } \\
{[1.08,2.7,4.5,9,13.5,18] .} \\
\text { Using carrier aggregation we can } \\
\text { obtain up to 54 MHz. }\end{array}$ \\
\hline $\begin{array}{l}\text { Traffic capacity of a PRB } \\
\text { [Mbps] }\end{array}$ & $\begin{array}{l}\text { Calculated according to the Band- } \\
\text { width associated to the set of PRBs } \\
\text { assigned, using the Shannon Ca- } \\
\text { pacity formula. } \\
\text { Min }=4.06 \text { Mbps, Max }=15.5 \\
\text { Mbps }\end{array}$ \\
\hline $\begin{array}{l}\text { Traffic capacity of an Un- } \\
\text { licensed Transmission Unit } \\
\text { [Mbps] }\end{array}$ & $\begin{array}{l}1.18 \text { Mbps - Capacity calculated } \\
\text { for 180 KHz of bandwidth with the } \\
700 \text { MHz band }\end{array}$ \\
\hline PRBs lease time & $\begin{array}{l}10 \text { time ticks (simulation time } \\
\text { units) }\end{array}$ \\
\hline $\begin{array}{l}\text { Unlicensed spectrum usage } \\
\text { time }\end{array}$ & $\begin{array}{l}\text { Case 1: Uniformly distributed be- } \\
\text { tween 90 and 110 time ticks. } \\
\text { Case 2: 10 time ticks (simulation } \\
\text { time units) }\end{array}$ \\
\hline $\begin{array}{l}\text { Total simulated market } \\
\text { time }\end{array}$ & $\begin{array}{l}5000 \text { time ticks: 3000 for warm- } \\
\text { up period and 2000 for active data } \\
\text { collection to determine the market } \\
\text { behavior }\end{array}$ \\
\hline Number of Spectrum Users & Variable: 4, 5,6, 10, 20 \\
\hline Mean traffic Demand & $\begin{array}{l}\text { Une Mbps } \\
\text { Time Traffic Inter-arrival } \\
\text { and 25 time ticks }\end{array}$ \\
\hline
\end{tabular}

\footnotetext{
${ }^{25}$ There were cases in which the value obtained through (8) did not match a standard-supported number of PRBs. In those situations we utilized to the closest allowable amount of PRBs.
}

\section{Results}

The results we present take into account the viability criteria introduced in subsection III-C. Given that the thresholds for viability evaluation are based on the analysis of simulation results, Table $\mathrm{V}$ presents the thresholds applicable to this new version of our model and the two scenarios we explored.

TABLE V: Evaluation Criteria for the Viability of the Simulated Spectrum Trading Markets

\begin{tabular}{|l|c|c|c|}
\hline \multicolumn{1}{|c|}{ Factor Pass } & Fail & $\begin{array}{c}\text { Score } \\
\text { Pass/Fail }\end{array}$ \\
\hline $\begin{array}{l}\text { Probability of empty } \\
\text { bid list }\end{array}$ & $=0$ & $>0$ & $1 /-1$ \\
\hline $\begin{array}{l}\text { Probability that } \\
\text { demand is greater } \\
\text { than supply }\end{array}$ & $\geq 10 \%$ & $<1 \%$ & $1 /-1$ \\
\hline Average cutoff price & N/A & $\leq 51$ & $0 /-1$ \\
\hline $\begin{array}{l}\text { Percentage of assigned } \\
\text { spectrum Average } \\
\text { across all } \\
\text { markets }\end{array}$ & $\begin{array}{c}<\text { Average } \\
\text { across all } \\
\text { markets }\end{array}$ & $1 /-1$ \\
\hline $\begin{array}{l}\text { Average number of un- } \\
\text { licensed spectrum units } \\
\text { per SU }\end{array}$ & N/A & $\geq 4$ & $0 /-1$ \\
\hline
\end{tabular}

1) Scenario 1: Our results from this first, conservative approach showed a slight improvement from those presented in the original version of SPECTRAD [13]. Nevertheless, as with the original model, we find market viability when $5 \leq R \leq 15$. These values of $\mathrm{R}$ corresponds to situations when there is no spectrum oversupply. Note that in the cases where $R=10$ and $R=15$, the maximum number of users we tested was 10 , due to our spectrum availability assumptions. Particularly, when $R=10$, all the tested configurations resulted in viable outcomes.

2) Scenario 2: The unlicensed spectrum usage assumption for this scenario gave as result positive outcomes for all the market configurations we tested. These viable outcomes included scenarios with spectrum oversupply and under-supply conditions. Evidently, this includes situations in which there are only a few participants in the market, which resembles more closely the current configuration of the telecommunications market.

\section{E. Discussion}

To evaluate the results obtained in this new version of the trading model, we have kept in mind that our main objective is to find a technically feasible 

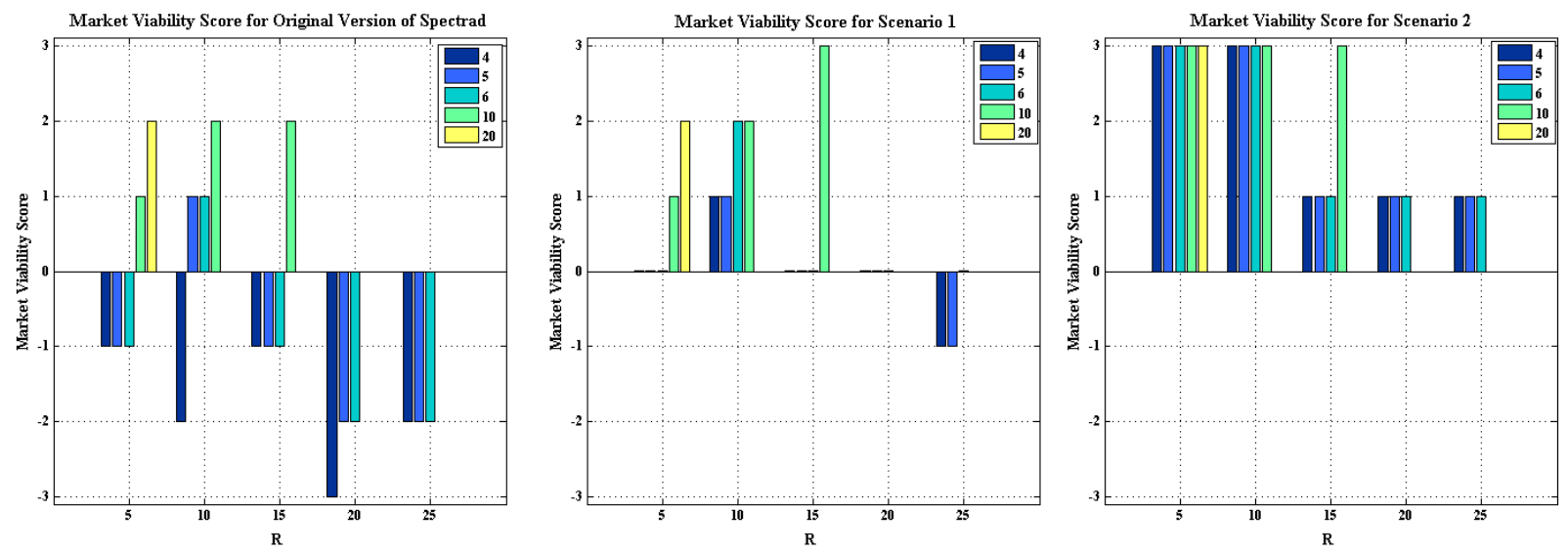

Fig. 6: Comparison of the Market Viability Scores for different SPECTRAD Model Versions. This figure shows results for relevant combinations of $R$ and numSLR values.

alternative that would bring thickness to the market while portraying practical market configurations. In this light, our study does not address the technical process that would be required to turn LTE-A PRBs into tradeable commodities; instead, our approach has been to use LTE-A PRBs as a proxy for defining a fungible and tradeable spectrum-related commodity. In figure 6, we include a comparison of the three different models of SPECTRAD as a means to visually evidence the changes that the incorporation of virtualization represents for overall market viability conditions.

Analyzing the results we obtained for our first scenario, we observed a slight improvement over the original SPECTRAD model. It is important to note that the fungibility conditions we have tested this time are more realistic, given that they are bounded within an existing and properly functioning technology, so it is an improvement over the fungibility constrained naked spectrum model.

In the second scenario, we found positive results in all the tested scenarios. One particular factor that contributes to this outcome is the fact that, throughout our market simulations, the probability of having an empty bid list was always equal to zero. This is a direct consequence of the (shorter) duration of the unlicensed spectrum usage period, which increases the possibilities for SLRs to participate in new bidding rounds.

To highlight the differences between Scenarios 1 and 2, in Figures 7 and 8, we show how these two scenarios compare in terms of market efficiency. Indeed, we can observe significant higher percentages

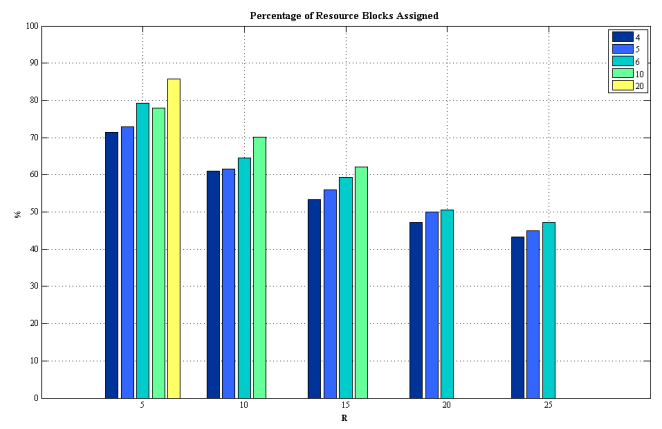

Fig. 7: Percentage of resources assigned in Scenario 1. Each color bar represents scenarios with 4, 5, 6, 10 and 20 SLRs where available.

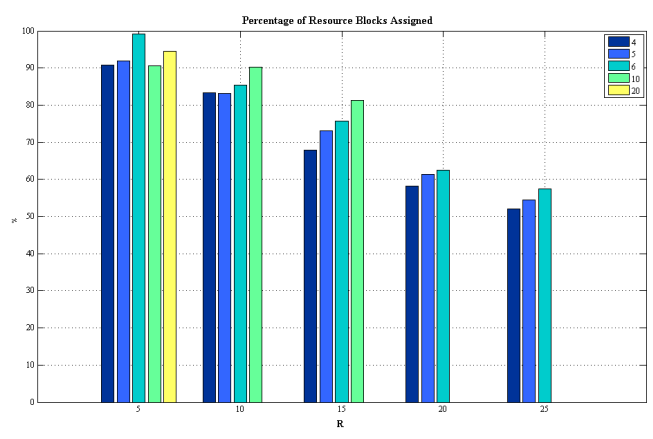

Fig. 8: Percentage of resources assigned in Scenario 2. Each color bar represents scenarios with 4, 5, 6, 10 and 20 SLRs where available.

of resources assigned when SLRs have the option of utilizing a more flexible and replaceable alternate technology.

These results are also a consequence of adding 
thickness to the market. In fact, in this section of our study we have focused on driving away from a one-to-one mapping of demand and supply, which is normally the case when naked spectrum is traded. The creation of the pool of resources and the further definition of the commodity to trade as capacity, allowed us to have multiple PRBs, from different sources being aggregated for satisfying the requirements of a given SLR. Certainly, this approach allowed us to scratch the surface on the opportunities provided by resource virtualization to enhance market viability. It should be noted that the focus of this work has been to provide a marketcentric analysis of spectrum trading; nevertheless, developing a marketplace for virtualized commodities requires a more comprehensive study of market and network factors that may shift to adapt to virtualized environments. Along these lines, a more complex market model for trading virtualized resources can be found in [42], [43].

To create the market model in [42], [43], we have started by exploring suitable network configurations and overall frameworks. In this way, our new market model is based in network concepts initially proposed by Doyle et al. in [24] and is placed within the Institutional Analysis and Development framework presented in [44], [45]. This has permitted us to create a richer picture of the factors influencing the development of the market we envision. This process required a re-evaluation of the environment where the market is deployed, the agents intervening in the transactions, their actions and how these can be used to provide feedback to the system and hence constantly improve its operations. For instance, one key addition is the inclusion of a Virtual Network Builder, which is a middleman or broker in charge of aggregating virtualized resources offered by sellers to meet the demand of spectrum buyers. We expect this middleman not only to ease the resource assignment process; but also to establish a trusting relationship with spectrum buyers. These modifications of the model permitted us to enhance our market study and shift from a market-centric approach to an institutional approach. Evidently, this new study required building an entirely new model, which does not allow for a straightforward comparison with SPECTRAD, hence remaining outside of the scope of this paper.

\section{CONCLUSION}

This paper reports on a broader research effort focused on studying secondary markets for radio spectrum. These markets are necessary if we wish to have a finer grained balance of spectrum supply and demand, if investors in carriers want a more realistic valuation of their spectrum assets, and if carriers have a hope of developing spectrumbased derivatives to help them offset their investment risk. The original work based on SPECTRAD showed that markets could work, but were subject to a "Goldilocks" condition (the right amount of spectrum for the demand) and having sufficient numbers of market participants. As we adapted the original model to more realistic spectrum conditions (through the mechanism of fungibility scores), these limitations were further exacerbated, suggesting that trading naked spectrum was not a promising way to achieving viable secondary markets. In practice, trading naked spectrum would be further encumbered by the physical infrastructure needed to deliver services using the traded spectrum (i.e., radios, antennas, towers, etc.). This infrastructure may or may not be suitable as frequency bands change.

What was (and is) needed is a different tradeable commodity. In the absence of such a model, we evaluated the use of PRBs in LTE as a proxy for a tradeable commodity that would be close to the physical layer but not bound by all of its constraints. While this is not a true virtual commodity, it has many of the essential characteristics that we were looking for. When implemented, we were able to show that trading markets in PRBs were thicker (more liquid) than naked spectrum. Thus, secondary markets may be viable for wireless connectivity, even if they are not for naked spectrum.

We kept the model from [13] as our basis for comparison throughout these models so we could compare across the different scenarios we modeled. That said, the outcomes of ABMs in general and the scoring approach we used to determine market viability in particular do not produce results that are suitable for statistical comparative analysis. Nonetheless, we are able to qualitatively compare the results of the different scenarios and draw conclusions that are suggestive of useful strategies.

The market model we utilize has been adaptable to different types of spectrum-related commodities, as shown in this paper, by exploring cases where 
naked and virtualized spectrum is traded. Additionally, our simulations show that SPECTRAD can support varying numbers of participants and resources available. This shows that our model scales well to various supply and demand conditions as well as different commodity definitions. It is also important to note that other auction mechanisms could be adapted to our model. Nevertheless, more complex settings that require different definitions of market participants and consider more comprehensive technical approaches may require a model restructuring process, and this is indeed part of our ongoing research efforts.

\section{FUTURE WORK}

Our research focuses on finding an appropriate, spectrum-derived commodity to trade in the market and defining how we can leverage technical advantages to increase market thickness. In turn, this would permit us to find market viability conditions that resemble those of existing telecommunications markets. With this aim, we are interested in deepening our study of more complex network definitions that rely on the resource pooling concept. This requires a study of the appropriate market participants, their goals and requirements, and how these influence the necessary market transactions. Additionally, we are interested in exploring different market mechanisms that may be suitable for spectrum trading. For instance, our future work will look into adapting matching theory for the development of a marketplace where spectrum buyers could express their requirements in more depth, noting that these requirements could go beyond willingness to pay and technical characteristics.

As part of a comprehensive spectrum markets study, we are also committed to incorporating additional economics, policy and governance considerations that could improve the framework we propose; hence converting it in a model that could be successfully adopted in practice.

\section{APPENDIX SPECTRUM FUNGIBILITY}

In this section, we discuss spectrum fungibility and its characterization, which we use in the agentbased simulations of the secondary spectrum markets we propose.

\section{A. Fungibility Basics}

Previous research seeking to establish the properties of electromagnetic spectrum has characterized it across multiple dimensions [1], [46] into what has been referred to as electrospace. One of these dimensions is frequency. Electromagnetic theory shows us that two frequency bands may have distinct properties and characteristics. From an economic perspective, these differences mean that two frequency bands are interchangeable only up to a certain degree and under specific conditions. Expressed differently, two units of electrospace that differ in frequency are not perfect (economic) substitutes, which represents significant limitations for the fungibility of spectrum as an economic commodity. ${ }^{26}$

Weiss et al. analyzed spectrum fungibility in [11] and developed a quantitative measure for spectrum fungibility based on various axes in which spectrum can vary (i.e., space, time, technology and regulation $)^{27}$. They proposed two measures of fungibility: a distance score (Euclidean distance) and a probabilistic score. ${ }^{28}$ The objective was to identify a measure of similarity between two bands that could be used by decision makers (and markets) to estimate the comparability of bands. Equations (9) and (10) show the general definition of these fungibility scores, where $d_{1}$ and $f_{1}$ are the distance and frequency parameters associated with the preferred option, while $d_{2}$ and $f_{2}$ correspond to the available options. The independent variables are scalars here, but could be generalized to vectors for comparing bands across multiple dimensions.

$$
\begin{aligned}
& \text { Distance Score }=\frac{\max \left(\left(d_{1}-d_{2}\right), 0\right)}{d_{1}} \\
& \text { Probabilistic Score }=\min \left(\frac{f_{1}}{f_{2}}, 1\right)
\end{aligned}
$$

The scores quantify the level of comparability and substitutability between available and preferred frequency bands, which could be used by spectrum buyers in order to assess the measure in which a

\footnotetext{
${ }^{26}$ Note that other dimensions of electrospace (e.g., time, location, regulations) may also create limitations on its fungibility.

${ }^{27}$ While the authors focused on the frequency dimension of electrospace, this theory could apply to other dimensions as well.

${ }^{28}$ The probabilistic score is not a probability in the mathematical sense; it rather represents the fraction of a specific characteristic (e.g., coverage, capacity, etc.) obtained when using an available (optional) frequency instead of the preferred one [11].
} 
frequency available could match the performance of their preferred frequency. Additionally, the scores could be used by a seller in order to determine the probability of success of a given transaction [11].

As the authors point out in [11], "when infrastructure and frequency bands can be assumed, then service providers do not trade spectrum access but rather for connectivity and reachability at a particular QoS". This supports our effort to define additional fungibility scores that aim at comparing spectrum-related attributes ${ }^{29}$.

\section{B. Calculating Spectrum Fungibility Scores}

In [12], we evaluated the fungibility score definition presented in [11] while applying empirical propagation models such as Okumura-Hata and COST 231 Walfisch-Ikegami. These models allowed us to take into account important physical and environmental characteristics associated with particular frequency bands. We studied how the received power changes according to the parameters considered in the different models, which permitted us to further explore fungibility in terms of capacity and coverage, which we explain next.

1) Coverage Fungibility Scores: One of the most important concerns for network management and dimensioning is the actual coverage that could be achieved with a specific frequency, under the conditions of the area where the system will be deployed. To this end, we developed a coverage fungibility score in order to provide a comparative measure of the coverage that can be achieved with two different frequency bands (i.e., available vs. preferred frequency).

To calculate this score, we utilized the link budget formula (11), where $P_{r}$ is the received power, $P_{t}$ is

\footnotetext{
${ }^{29}$ These fungibility scores map to the economic concept of rent. Ricardo [47] defines rent as "the difference between the produce obtained by the employment of two equal quantities of capital and labor". More generally, as expressed in ,"the economic rent of an asset is the added value or the net return to investment, of using that asset instead of the least efficient, or least desirable, alternative asset available" [48]. In consequence, economic rent "represents the additional value a producer is willing to pay to use the characteristics and quality of an asset". The authors further explain that it is also expected that as the quality of the resources diminishes, the rent paid on those resources will be reduced as well [48]. We find that the use of fungibility scores could represent a practical means to capture this difference between distinct frequency bands. If we further map this to a spectrum trading environment, fungibility scores could be utilized to find the difference between the frequency bands that are available in the market and those that a user prefers and project this difference to spectrum valuation.
}

the transmitted power, $G_{t}$ and $G_{r}$ are the transmitter and receiver gains, respectively, and $L_{p}$ is the path loss. ${ }^{30}$ We worked with a specific minimum required received power, which permitted us to calculate the maximum allowable path loss, and thus determine the distance (from the transmitter) associated with this value. This distance would correspond to the maximum cell radius, or in other words, maximum coverage.

$$
P_{r}=P_{t}(d B m)+G_{t}(d B)+G_{r}(d B)-L_{p}(d B)
$$

We built our coverage fungibility score by comparing the maximum coverage achieved with the preferred frequency, $f_{1}$, and the available frequency $f_{2}$. Table VI shows the parameters that we utilized for our calculations. ${ }^{31}$

2) Capacity Fungibility Scores: The capacity scores permit us to assess what capacity, when calculated with different frequency bands, may be considered fungible. To do this, we utilized the Shannon-Hartley Information Capacity theorem (12), which enables us to determine the maximum rate achievable in a specific channel with a given bandwidth and under the presence of noise.

$$
C=B \log _{2}(1+S N R)
$$

For the signal value, we utilized the power received at a specific distance (i.e., fixed distance or cell-edge), and the noise power was estimated using (14), where $F$ is the noise figure of the receiver, $k$ is the Boltzmann's constant, $T$ is the reference temperature $(290 \mathrm{~K})$ and $B$ is the applicable bandwidth.

$$
\begin{aligned}
N & =F k T B \\
& =F(d B)+k(d B m / H z / K)+T(d B m)+B(d B m)
\end{aligned}
$$

In the analysis presented in [12], the capacity fungibility score was determined by comparing the capacity resulting from utilizing an available frequency (available capacity) with the capacity achievable with the preferred frequency (reference capacity). Note that the path-loss impacts the received power and hence the capacity. Thus, the capacity at 1900 $\mathrm{MHz}$ with a given unit of bandwidth would be

\footnotetext{
${ }^{30}$ Path loss was calculated using the aforementioned empirical propagation models: Okumura-Hata and COST 231 WalfischIkegami.

${ }^{31}$ The values included in this table, and thus utilized for our calculations, correspond to those utilized in [13] and [11]. This permitted us to maintain those works as a measure for comparability.
} 
TABLE VI: Reference Parameters Utilized for the Calculation of Fungibility Scores

\begin{tabular}{|l|c|}
\hline \multicolumn{1}{|c|}{ Parameter } & Reference Value \\
\hline Preferred Frequencies & $\begin{array}{c}700,1000,1500,1700, \\
1900 \text { and } 2000 \mathrm{MHz}\end{array}$ \\
\hline Available Frequency & $1900 \mathrm{MHz}$ \\
\hline Bandwidth & $200 \mathrm{KHz}$ \\
\hline $\begin{array}{l}\text { Distance from trans- } \\
\text { mitter }\end{array}$ & $1 \mathrm{Km}$ \\
\hline Transmitted Power & $1 \mathrm{~mW}$ \\
\hline $\begin{array}{l}\text { Minimum Required } \\
\text { Received Power }\end{array}$ & $-80 \mathrm{dBm}$ \\
\hline Base Station Height & $50 \mathrm{~m}$ \\
\hline $\begin{array}{l}\text { Geographic } \\
\text { Environment }\end{array}$ & $1 \mathrm{~m}$ \\
\hline Mobile Antenna Height & $0 \mathrm{~dB}$ \\
\hline Noise Figure & $20 \mathrm{~m}$ \\
\hline Width of road & $40 \mathrm{~m}$ \\
\hline Building separation & $15 \mathrm{~m}$ \\
\hline Building height & 90 \\
\hline Phi & \\
\hline
\end{tabular}

smaller than the capacity at $700 \mathrm{MHz}$ for the same amount of bandwidth. In this way, we calculated the available capacity (e.g., capacity obtained with 1900 $\mathrm{MHz}$ ) considering different values of bandwidth. The reference capacity was calculated utilizing a fixed reference bandwidth (e.g., preferred frequency of $700 \mathrm{MHz}$ operating with $200 \mathrm{MHz}$ of bandwidth). For the noise power, we used (14) with the corresponding available/preferred frequency and applicable values of bandwidth. Finally, the signal power was calculated using the COST 231 WalfischIkegami propagation model, while considering the parameters shown in Table VI.

By comparing the resulting capacities, we obtained probabilistic and distance fungibility scores. We also determined what bandwidth would be required with an available frequency to match the capacity obtained with the preferred band. We find that the performance gap between the compared frequencies decreases as the capacity probabilistic score approaches 1 . From this, we can determine the bandwidth requirements for frequency substitutability.

\section{ACKNOWLEDGMENT}

We sincerely thank the reviewers for their insightful comments and recommendations.

This work was supported in part by the U.S. National Science Foundation under Grant 1247546.

\section{REFERENCES}

[1] R. Matheson and A. C. Morris, "The technical basis for spectrum rights: Policies to enhance market efficiency," Telecommunications Policy, vol. 36, no. 9, pp. 783-792, October 2012.

[2] S. M. Benjamin, H. A. Shelanski, J. B. Speta, and P. J. Weiser, Telecommunications Law and Policy, 3rd ed. Carolina Academic Press, 2012.

[3] M. B. Weiss, W. H. Lehr, L. Cui, and M. Altamaimi, "Enforcement in dynamic spectrum access systems," in Telecommunications Policy Research Conference. Telecommunications Policy Research Conference, September 2012. [Online]. Available: http://d-scholarship.pitt.edu/13609/

[4] M. B. Weiss, W. Lehr, A. Acker, and M. M. Gomez, "Sociotechnical considerations for spectrum acess system (sas) design," in Dynamic Spectrum Access Networks (DYSPAN), IEEE International Symposium on, (forthcoming).

[5] L. Cui, M. M. Gomez, and M. B. Weiss, "Dimensions of cooperative spectrum sharing: Rights and enforcement," New Frontiers in Dynamic Spectrum Access Networks (DySPAN), 2014.

[6] J. W. Mayo and S. Wallsten, "Enabling efficient wireless communications: The role of secondary spectrum markets." Information Economics and Policy, vol. 22, no. 1, pp. 61-72, 2010.

[7] R. H. Coase, "The federal communications commission," Journal of law and economics, pp. 1-40, 1959.

[8] FCC. (2003) Report and order and further notice of proposed rulemaking. promoting efficient use of spectrum through elimination of barriers to the development of secondary markets. [Online]. Available: https://apps.fcc.gov/ edocs $\_$public/attachmatch/FCC-03-113A1.pdf

[9] A. E. Roth, Who Gets What and Why. Houghton Mifflin Harcourt Publishing Company, 2015.

[10] C. E. Caicedo, "Technical architectures and economic conditions for viable spectrum trading markets," Ph.D. dissertation, University of Pittsburgh, 2009.

[11] M. Weiss, P. Krishnamurthy, L. E. Doyle, and K. Pelechrinis, "When is electromagnetic spectrum fungible?" in Dynamic Spectrum Access Networks (DYSPAN), 2012 IEEE International Symposium on. IEEE, 2012, pp. 349-357.

[12] M. M. Gomez and M. B. Weiss, "How do limitations in spectrum fungibility impact spectrum trading?" Telecommunications Policy Research Conference, September 2013.

[13] C. E. Caicedo and M. B. Weiss, "The viability of spectrum trading markets." New Frontiers in Dynamic Spectrum, 2010 IEEE Symposium on, April 2010.

[14] S. Sengupta and M. Chatterjee, "Designing auction mechanisms for dynamic spectrum access," Mobile Networks and Applications, vol. 13, no. 5, pp. 498-515, 2008.

[15] X. Zhou, S. Gandhi, S. Suri, and H. Zheng, "ebay in the sky: Strategy-proof wireless spectrum auctions," in Proceedings of the 14th ACM international conference on Mobile computing and networking. ACM, 2008, pp. 2-13.

[16] X. Zhou and H. Zheng, "Trust: A general framework for truthful double spectrum auctions," in INFOCOM 2009, IEEE. IEEE, 2009, pp. 999-1007.

[17] T. K. Forde, I. Macaluso, and L. E. Doyle, "Exclusive sharing and virtualization of the cellular network," New Frontiers in Dynamic Spectrum Access Networks (DySPAN), 2011 IEEE Symposium on., 2011.

[18] A. Gopinathan and Z. Li, "Strategyproof auctions for balancing social welfare and fairness in secondary spectrum markets," in INFOCOM, 2011 Proceedings IEEE. IEEE, 2011, pp. 30203028. 
[19] J. M. Peha and S. Panichpapiboon, "Real-time secondary markets for spectrum," Telecommunications Policy, vol. 28, no. 7, pp. 603-618, 2004.

[20] M. J. Marcus, "Real time spectrum markets and interruptible spectrum: New concepts of spectrum use enabled by cognitive radio," in New Frontiers in Dynamic Spectrum Access Networks, 2005. DySPAN 2005. 2005 First IEEE International Symposium on. IEEE, 2005, pp. 512-517.

[21] S. Gandhi, C. Buragohain, L. Cao, H. Zheng, and S. Suri, "A general framework for wireless spectrum auctions," in New Frontiers in Dynamic Spectrum Access Networks, 2007. DySPAN 2007. 2nd IEEE International Symposium on. IEEE, 2007, pp. 22-33.

[22] — "Towards real-time dynamic spectrum auctions," Computer Networks, vol. 52, no. 4, pp. 879-897, 2008.

[23] S. Mishra and S. Roy, "Market mechanisms for dynamic spectrum access (dsa)," IEEE Transactions on Wireless Communications, vol. 17, no. 5, pp. 3071-3081, 2018.

[24] L. Doyle, J. Kibilda, T. K. Forde, and L. DaSilva, "Spectrum without bounds, networks without borders," Proceedings of the IEEE, vol. 102, no. 3, pp. 351-365, March 2014.

[25] P. Cramton and L. Doyle, "Open access wireless markets," Telecommunications Policy, vol. 41, no. 5-6, pp. 379-390, 2017.

[26] B. Lorenzo, A. S. Shafigh, J. Liu, F. J. González-Castaño, and Y. Fang, "Data and spectrum trading policies in a trusted cognitive dynamic network architecture," IEEE/ACM Transactions on Networking, 2018.

[27] A. W. Min, X. Zhang, J. Choi, and K. G. Shin, "Exploiting spectrum heterogeneity in dynamic spectrum market," IEEE Transactions on Mobile Computing, vol. 11, no. 12, pp. 20202032, 2012.

[28] L. Duan, J. Huang, and B. Shou, "Investment and pricing with spectrum uncertainty: A cognitive operator's perspective," IEEE Transactions on Mobile Computing, vol. 10, no. 11, pp. 15901604, 2011.

[29] D. Niyato and E. Hossain, "Spectrum trading in cognitive radio networks: A market-equilibrium-based approach," Wireless Communications, IEEE, vol. 15, no. 6, pp. 71-80, 2008.

[30] D. Niyato, E. Hossain, and Z. Han, "Dynamics of multipleseller and multiple-buyer spectrum trading in cognitive radio networks: A game-theoretic modeling approach," IEEE Transactions on Mobile Computing, vol. 8, no. 8, pp. 1009-1022, 2009.

[31] D. Niyato and E. Hossain, "Competitive pricing for spectrum sharing in cognitive radio networks: Dynamic game, inefficiency of nash equilibrium, and collusion," IEEE journal on selected areas in communications, vol. 26, no. 1, 2008.

[32] U. Wilensky and W. Rand, An introduction to agent-based modeling: modeling natural, social, and engineered complex systems with NetLogo. MIT Press, 2015.

[33] L. Cui, M. B. Weiss, B. Morel, and D. Tipper, "Risk and decision analysis of dynamic spectrum access," Telecommunications Policy, vol. 41, no. 5, pp. 405 - 421, 2017, optimising Spectrum Use. [Online]. Available: http://www. sciencedirect.com/science/article/pii/S0308596117300460

[34] J. M. Perloff, Microeconomics: theory and applications with calculus, 2008.

[35] M. M. Gomez, L. Cui, and M. B. H. Weiss, "Trading wireless capacity through spectrum virtualization using lte-a," TPRC Conference Paper, 2014.

[36] A. Wang, M. Iyer, R. Dutta, G. N. Rouskas, and I. Baldine, "Network virtualization: Technologies, perspectives, and frontiers." Lightwave Technology, Journal of, vol. 31, no. 4, pp. 523-537, 2013.
[37] T. Forde and L. E. Doyle, "Cellular clouds," Telecommunications Policy, vol. 37, no. 2-3, pp. 194-207, 2013.

[38] H. Wen, P. K. Tiwary, and T. Le-Ngoc, Wireless Virtualization. Springer, 2013.

[39] Y. Zaki, L. Zhao, C. Goerg, and A. Timm-Giel, "Lte mobile network virtualization," Mobile Networks and Applications, vol. 16, no. 4, pp. 424-432, 2011.

[40] S. Ahmadi, LTE-Advanced: A Practical Systems Approach to Understanding 3GPP LTE Releases 10 and 11 Radio Access Technologies. Academic Press, 2013.

[41] 3GPP, "Evolved universal terrestrial radio access (e-utra); base station (bs) radio transmission and reception (3gpp ts 36.104 version 12.3.0 release 12)," 3GPP, TS 12.3.0:V12.3.0, March 2014.

[42] M. M. Gomez, "Secondary spectrum markets: from 'naked' spectrum to virtualized commodities," Ph.D. dissertation, University of Pittsburgh, 2017.

[43] M. M. Gomez, M. B. Weiss, G. McHenry, and L. Doyle, "Matching markets for spectrum sharing," TPRC Conference Paper, 2017. [Online]. Available: https://ssrn.com/abstract= 2944197

[44] E. Ostrom, "Background on the institutional analysis and development framework," Policy Studies Journal, vol. 39, no. 1, pp. 7-27, 2011.

[45] M. D. McGinnis, "An introduction to iad and the language of the ostrom workshop: a simple guide to a complex framework," Policy Studies Journal, vol. 39, no. 1, pp. 169-183, 2011.

[46] A. S. DeVany, R. D. Eckert, C. J. Meyers, D. J. O'Hara, and R. C. Scott, "A property system for market allocation of the electromagnetic spectrum: A legal-economic-engineering study." Stanford Law Review, pp. 1499-1561, 1969.

[47] D. Ricardo, "On rent," in On the Principles of Political Economy and Taxation. Library of Economics and Liberty, 1821.

[48] C. Bazelon, "The economic basis of spectrum value: Pairing aws-3 with the $1755 \mathrm{mhz}$ band is more valuable than pairing it with frequencies from the $1690 \mathrm{mhz}$ band," The Brattle Group, Washington DC, 2011. 